\title{
Bioreduction of Silver Nanoparticles Using Different Plant Extracts and Its Bioactivity against $E$. coli and $A$. Niger
}

\author{
R. S. Choudhary ${ }^{1}$, N. B. Bhamare ${ }^{2}$, B. V. Mahure ${ }^{3}$ \\ ${ }^{I}$ Dept. of Plant Biotechnology, K. K. Wagh College of Agricultural Biotechnology, Saraswati Nagar, Panchwati, \\ Nashik- 422 003, Maharashtra, India. \\ ${ }^{2}$ Department of Environment Science, K.T.H.M. College Nashik-422 003, Maharashtra, India. \\ ${ }^{3}$ Dept. of Biochemistry and Molecular Biology, K. K. Wagh College of Agricultural Biotechnology, \\ Saraswati Nagar, Panchwati, Nashik- 422 003, Maharashtra, India.
}

\begin{abstract}
The study of assembling, controlling and manipulating matter on molecular or atomic size is called Nanotechnology in brief known as Nano. Nanotechnology is the study of material of lesser than size $100 \mathrm{~nm}$ or smaller in size. Silver nanoparticles are silver particles between $1 \mathrm{~nm}$ and $100 \mathrm{~nm}$ in size. Silver is well known for its excellent conductivity and antimicrobial effects. They have a much larger surface area, higher efficiency while using less material. They have been used as an ingredient in biocides, in transparent conductive inks and pastes, and in various consumer and industrial products that need enhanced anti-microbial properties. In the present research programme we have synthesised silver nanoparticles using the extract of Cassia auriculata, Datura metel, Ocimum sanctum and Carica papaya plants. The principle of green synthesis of silver nano particles has been used. The botany of plants have been furnished along with the figure of the plant. The UV visible spectra of the silver nano particles have also been described. The synthesised nano particles are evaluated for its antimicrobial activity against bacterial and fungal pathogens. Novelty of this present study is that the plant extract is very cost effective and eco friendly and thus can be economic and effective for the large scale synthesis of silver nano particles applicable for various drug therapies.
\end{abstract}

Keywords: Silver nano particles, anti-microbial activity, Cassia auriculata, Datura metel, Ocimum sanctum, Carica papaya.

\section{Introduction}

Nanotechnology is one of the modern techniques of material science.The small sized nano particles mean they exhibit enhanced or different properties when compared with the bulk material. The extremely small size of nano particles having a large surface area relative to their volume. The main phytochemicals responsible for the synthesis of nanoparticles are terpenoids, flavones, ketones, aldehyde amides etc. The most effectively studied nanoparticles today are those made from noble metals, in particular Silver (Ag), Platinum (Pt), Gold $\mathrm{Au}$ ) and Palladium (Pd). Especially silver have drawn the attention of scientists because of their extensive application in the development of new technology in the areas of electronics, material science and medicine at the nano scale. New applications of nano particles and nano materials are emerging rapidly. Nano silver particles have found tremendous application in the field of high sensitivity biomolecular detection and diagnostics, antimicrobials, therapeutics, catalysis and microelectronics. Therefor there is still need for economic commercially visible as well as environmentally clean synthesis route to synthesise silver nano particles.

In the present research programme silver nano particles was synthesised using the extract of Cassia auriculata, Datura metel, Ocimum sanctum and Carica papaya plants. Cassia auriculata is a common plant, profoundly used as antipyretic, antidiabetic, antiperoxidative, antihyperglyceamic conjunctivitis, opthalmia, ulcers, leprosy, skin and liver diseases [1]. Datura metel is a shrub-like perennial herb popular for its phytomedicinal values to cure diseases like asthma, cough, convulsion and insanity. Ocimum sanctum is a medicinal herb abundantly found in India. The leaves have been used traditionally in treatment for many infections. Carica papaya fruit and seeds contain antimicrobial properties against $E$. coli and have effect in toxicity induced kidney failure. The main objective of this study includes i) to synthesised and characterized silver nanoparticles by biological method ii) to examine the antimicrobial potential of silver nanoparticles against pathogen like; E. coli and A. niger.

\subsection{Collection of plant samples}

\section{Material and Methods}

The young plants of Ocimum sanctum leafs, unripe Carica papaya fruit, Cassia auriculata leaf \& Datura metel flower were collected from Nashik region, Maharashtra (Figure 1). The plant species were identified by using the standard morphological characteristic features (Table 1). 


\subsection{Preparation of Datura metel flower}

The collected sample (D. metel) was brought to separate contamination such as adhering impurities, sand particles and dust. Then the sample was soaked in distilled water. The flower was shade dried for 14 days. The dried flower was ground and stored in air tight containers [2].

\subsubsection{Preparation of aqueous extract of Datura metel}

The powder obtained was extracted with distilled water. To $5 \mathrm{~g}$ of powdered sample, $100 \mathrm{ml}$ of distilled water was added and boiled to $60-70{ }^{\circ} \mathrm{C}$ for about $10 \mathrm{~min}$. Then the resulting crude extracts were filtered through Whatman no.1 filter paper $(0.25 \mu \mathrm{m})$ and stored in refrigerator.

\subsubsection{Synthesis of silver nonoparticles by Datura metel}

$\mathrm{AgNO}_{3}$ of $1 \mathrm{mM}$ was prepared by adding $0.015 \mathrm{~g}$ of $\mathrm{AgNO}_{3}$ to $90 \mathrm{ml}$ of distilled water and used for the synthesis of silver nanoparticles. Then $10 \mathrm{ml}$ of $D$. metel flower extract was added into $90 \mathrm{ml}$ of prepared aqueous solution of $1 \mathrm{mM} \mathrm{AgNO}_{3}$ for reduction into $\mathrm{Ag}^{+}$ions and kept in magnetic stirrer for 1 hrs at room temperature [2].

\subsection{Preparation of aqueous extract of Ocimum sanctum leaves}

$20 \mathrm{gm}$ of fresh leaves of Ocimum sanctum were washed thoroughly with distilled water and then cut into small pieces. These finely cut pieces were then mixed with $100 \mathrm{ml}$ doubled-distilled water and this mixture was kept for boiling for a period of 5 minutes. After cooling, it was filtered through Whatman no. 1 filter paper and stored in refrigerator.

\subsubsection{Synthesis of silver nonoparticles by Ocimum sanctum}

$10 \mathrm{ml}$ of aqueous extract of Ocimum sanctum leaves was added to $90 \mathrm{ml}$ of silver nitrate solution so as to make its final concentration to $3 \mathrm{mM}$. The solution was allowed to react at room temperature. Periodic sampling after 30 minutes was carried out to monitor the formation of AgNPs.

\subsection{Preparation of aqueous extract of Carica papaya fruit extract}

Green unripe Carica papaya fruits were used to make the aqueous extract. Unripe fruit weighing $25 \mathrm{~g}$ were thoroughly washed in distilled water, dried, cut into fine pieces and were crushed into $100 \mathrm{ml}$ sterile distilled water and filtered through Whatman No.1 filter paper and stored in refrigerator [3].

\subsubsection{Synthesis of silver nanoparticles by Carica papaya}

$1 \mathrm{mM}$ aqueous solution of $\mathrm{AgNO}_{3}$ was prepared and used for the synthesis of silver nanoparticles. $10 \mathrm{ml}$ of papaya fruit extract was added into $90 \mathrm{ml}$ of aqueous solution of $1 \mathrm{mM}$ silver nitrate for reduction into $\mathrm{Ag}^{+}$ ions and kept at room temperature for 5 hours.

\subsection{Preparation of aqueous extract of Cassia auriculata leaf}

The healthy leaves of Cassia auriculata were collected. The leaves were gently washed with soap solution and bavistine to remove the dust and any other contaminant then shade dried at room temperature for about 8-10 days. Dried leaves were powdered and $10 \%$ of aqueous extract was prepared by boiling the powder in distilled water for 5-10 minutes, filtered and used as reducing agent [4].

\subsubsection{Synthesis of silver nanoparticles by Cassia auriculata}

$10 \mathrm{ml}$ of aqueous leaf extract was added to $100 \mathrm{ml}$ of $3 \mathrm{mM} \mathrm{AgNO}_{3}$ solution and kept at room temperature. The colour of the solution started changing within 5-10 minutes from yellow to dark brown.

\subsection{Characterization of silver nano particles via UV-vis spectroscopy}

The reduction of silver ions was monitored by measuring the UV-Vis spectrum of the plant extact medium in range of 270, 350, 450 and $520 \mathrm{~nm}$ respectively for two times i.e. after $30 \mathrm{~min}$. and $5 \mathrm{hrs}$. taking small aliquot of the sample. UV-Vis spectral analysis was done by using UV-Vis spectrophotometer (Systronics, India).

\subsection{Antimicrobial activity of silver nanoparticles}

\subsubsection{Antibacterial assay}

By agar well diffusion method the antibacterial activities of AgNPs synthesised by four plant extract were studied [6]. The LB (Luria Bertoni) media was prepared and overnight grown bacterial suspension of E.coli was swabbed on the plates. Ethanol and antibiotic chloramphenicol was used as a positive control. These 
plates were incubated at $37{ }^{\circ} \mathrm{C}$ for 24 hours in bacteriological incubator and the zone of inhibition was measured.

\subsubsection{Antifungal assay}

The potato dextrose agar plates were prepared and fungal cultures of A. niger was swabbed on these plates [7]. Silver nanoparticles solution $(100 \mu \mathrm{l})$ placed in the agar plate and kept for incubation at $37{ }^{\circ} \mathrm{C}$ for 24 hrs. in bacteriological incubator. Ethanol and antibiotic chloramphenicol was used as a positive control and zone of inhibition was measured after incubation period.

\section{Synthesis of silver nanoparticles}

\section{Result and Discussion}

Silver nitrate exhibit colourlessness in distilled water. When the plant extract was mixed in the aqueous solution of the silver ion, it started to change the colour from colourless to various different colours due to reduction of silver ion, which may be the indication of formation silver nanoparticles. In this work all four plant extract solutions after incubation at room temperature were showed the colour change from yellowish to dark brown. All the samples and their synthesis parameters are listed in Table 2.

\section{Characterization of silver nanoparticles by UV-vis spectral analysis}

The UV-vis spectrophotometer would be used to observe size and shape controlled nanoparticles in aqueous solution. The UV-vis spectra of the silver nanoparticles showed a well defined surface plasmon band centered at around $270 \mathrm{~nm}, 350 \mathrm{~nm}, 450 \mathrm{~nm}$ and $520 \mathrm{~nm}$ at different time interval as shown in Figure 2. This is the characteristic of silver nanoparticles and clearly indicates the formation of nanoparticles in solution. The plasmon bands are broad with an absorption tail in the longer wavelengths and increase the reading. This could be in practice due to the size distribution of the particle.

The highest peak was observed by Cassia auriculata followed by Datura metel then Carica papaya and last was Ocimum sanctum at all UV- vis range. The average highest peak was observed at $350 \mathrm{~nm}$ by all four plants followed by $450 \mathrm{~nm}, 520 \mathrm{~nm}$ and $270 \mathrm{~nm}$ resp. The individual highest peak was observed at $270 \mathrm{~nm}$ after $30 \mathrm{~min}$. in Cassia auriculata plant extract. Absorption spectra and broadening of peak of silver nanoparticles formed in the reaction indicated that the particles are poly dispersed.

\section{Antimicrobial activity against bacterial and fungal species}

Silver nitrate has long been considered as a powerful and natural antibiotic and antibacterial agent. Silver nanoparticles exhibit antimicrobial properties against bacterial pathogens with close attachment of the nanoparticles themselves with the microbial cells. The antimicrobial activity of silver nanoparticles has been investigated against Escherichia coli. The zones of inhibition of E.coli against AgNPs, ethanol, plant extract, and choromphenical (standard) was observed (Table 3). The silver nanoparticles obtain very strong inhibitory $(+++)$ action and no zone of inhibition was observed for ethanol. A very small but noticeable zone of inhibition was observed for plant extracts. After sufficient incubation the nanoparticles showed an inhibition zone from 5 to $10 \mathrm{~mm}$ in E. coli. Cassia auriculata and Ocimum sanctum showed highest antibacterial activity against $E$. coli. Similar observation made by $[3,8,9]$ in their research work.

Similarly the antifungal activity of silver nanoparticle has been investigated against Aspergillus niger. The zones of inhibition of Aspergillus niger against AgNPs, ethanol, plant extract and choromphenical (standard) was observed (Table 3). The silver nanoparticles obtain strong inhibitory (+) action and no zone of inhibition was seen for ethanol. A very small but noticeable zone of inhibition was observed for plant extracts. After sufficient incubation the nanoparticles showed an inhibition zone near to $5 \mathrm{~mm}$ against A. niger by Cassia auriculata and Ocimum sanctum. Similarly $[10,11]$ carried out the antimicrobial activity of silver nanoparticles against the bacteria $E$. coli \& fungi A. niger.

\section{Conclusion}

The present study concluded that the plants Carica papaya, Datura metel, Ocimum sanctum and Cassia auriculata can be used as an excellent source for synthesing the silver nanoparticles. In our study we used fruit, flower, and leaf as a source which is easily available, cost effective, environment friendly. The primary confirmatory for the silver nanoparticles was colour changes and UV vis absorption spectra of silver nano particles formed peak at $270 \mathrm{~nm}, 350 \mathrm{~nm}$ and $450 \mathrm{~nm}$. The Cassia auriculata have maximum absorbancy in UV visible spectrophotometer. The formed AgNPs are small in size, highly stable, and have significant antimicrobial activity against E. coli and A. niger. Cassia auriculata and Ocimum sanctum shows the highest sensitivity compared to the other two plants. So green sysnthesis of nanoparticles can be ecofriendly in largescale synthesis. The application of nanoparticles for commercial scale agricultural applications in the management of plant disease such as powdery mildew of cucumber and pumpkin. The silver nanoparticles 
synthesized via green route are highly toxic to multi drug resistant bacteria \& fungi. Hence has a great potential in biomedical applications. The present study showed a easy, fast and inexpensive way to synthesized silver nanoparticles.

\section{Acknowledgement}

The authors would like to thank Chairman and Principal of K. K. Wagh College of Agricultural Biotechnology, Nashik for the support of chemicals and equipments for this research.

\section{References}

[1]. A. Parveen, A.S. Roy, and S. Rao, Biosynthesis and characterization of silver nanoparticles from Cassia auriculata leaf extract and in vitro evaluation of Antimicrobial activity. Int J Appl Biol Pharm Technol 3 (2), 2012, 222-228.

[2]. S. Prashanth, I. Menaka, R. Muthezhilan, N.K. Sharma, Synthesis of plant-mediated silver nano particles using medicinal plant extract and evaluation of its anti microbial activities. Int J Eng Sci Tech 3(8): 2011, 6235-6250.

[3]. K. Ratika, and A. Vedpriya, Biosynthesis and characterization of silver nanoparticles from aqueous leaf extracts of Carica papaya and its antibacterial activity. Int J Nanomater Biostruct 3(1): 2013, 17-20.

[4]. C. Udayasoorian, K. Vinoth, and R.M. Jayabalakrishnan, Extracellular synthesis of silver nanoparticles using leaf extract of Cassia auriculata. Digest J Nanomater Biostruct 6(1), 2011, 279-283.

[5]. D. Jain, H. K. Daima, S. Kachhwaha, and S. L. Kothari, Synthesis of plant mediated silver nanoparticles using papaya fruit extract and evaluation of their antimicrobial activities. Digest J Nanomater. Biostruct 4(4), 2009, $723-727$.

[6]. G.M. Sulaimal, H.M. Wasnaa, R.M. Thorria, A.A.A. Al-Amiery, A.A.H. Kadhum and A.B. Mohamad, Green synthesis, antimicrobial and cytotoxic effects of silver nanoparticles using Eucalyptus chapmaniana leaves extract. Asian Pac J Trop Biomed. 3(1): 2013, 58-63.

[7]. S. Velavan, P. Arivoli and K. Mahadevan, Biological reduction of silver nanoparticles using Cassia auriculata flower extract and evaluation of their in vitro antioxidant activities. Nanosci Nanotechnol Int J 2(4): 2012, 30-35.

[8]. C. Nethradevi, S. Padmanaban, S. Renganathan, Green synthesis of silver nanoparticles using Datura metel flower extract and evaluation of their antimicrobial activity. Int J. Nanomater Biostruct 2(2): 2012, 16-21.

[9]. A.K. Ojha, J. Rout, S. Behera, and P.L. Nayak, Green synthesis and characterization of zero valent silver nanoparticles from the leaf extract of Datura metel. Int J Pharma Res Allied Sci 2 (1): 2013, 31-35.

[10]. C., Ramteke, T. Chakrabharti, B.K. Sarangi, and R.A. Pankey, Synthesis of silver nanoparticles from the aqueous extract of Ocimum sanctum for enhanced antibacterial activity. J Chem vol. 2013, Article ID 278925, 7 pages, 2013. doi:10.1155/2013/278925.

[11]. M. Linga Rao, N. Savithramma, K. Rukmini and P. S. Devi, Antimicrobial activity of silver nanoparticles synthesized by medicinal plants. Int J ChemTech Res. 3(3), 2011, 1394-1402.

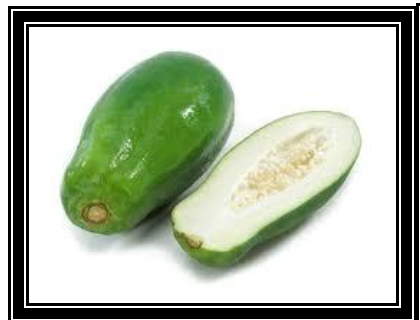

Carica papaya

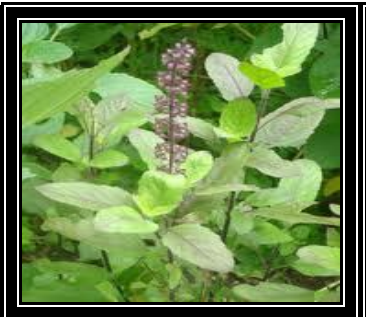

Ocimum sanctum

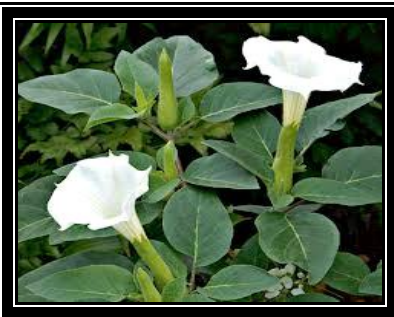

Datura metel

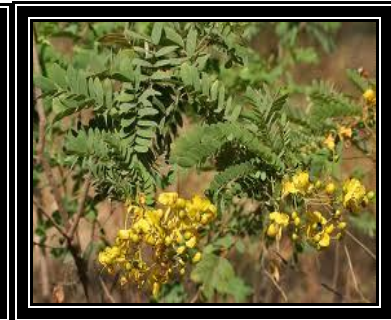

Cassia auriculata

Figure 1. Plant samples used for the synthesis of silver nanoparticles

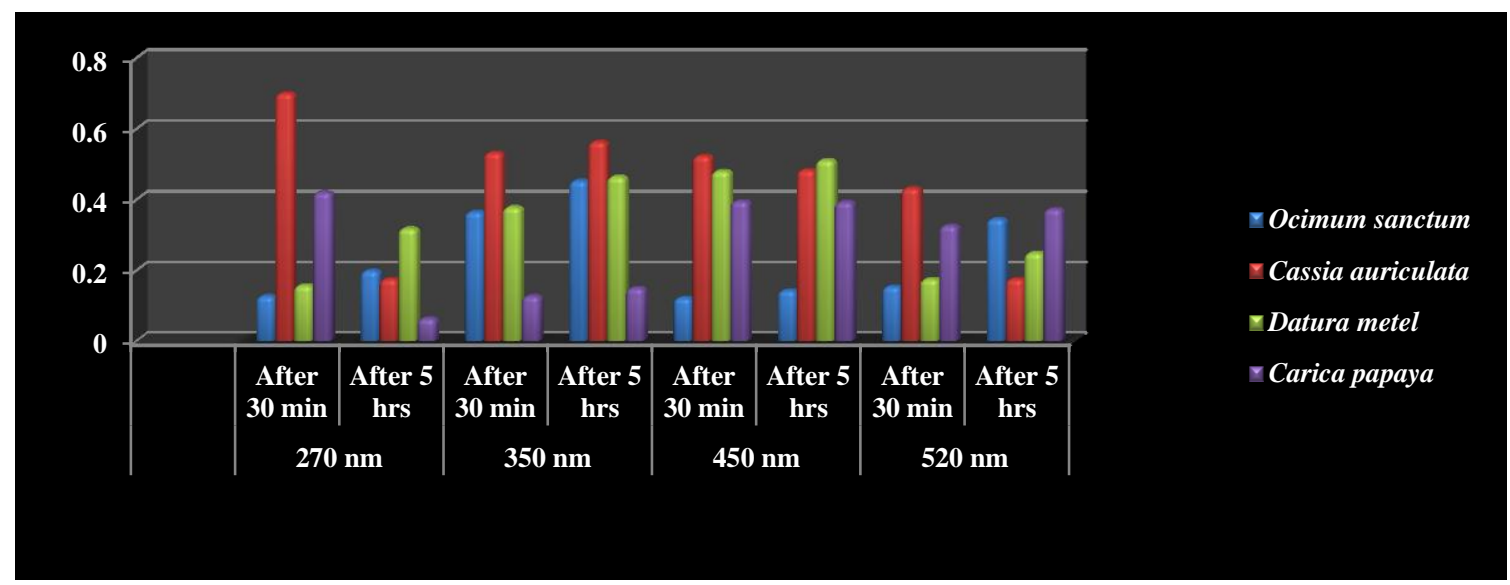

Figure 2. UV -Vis absorption spectrum of silver nanoparticles synthesiesd by Ocimum sanctum, Cassia auriculata, Datura metel and Cassia auriculata 
Bioreduction of Silver Nanoparticles Using Different Plant Extracts and Its Bioactivity against .....

Table 1. Botanical classification of plant samples and plant parts which was used in present investigation

\begin{tabular}{|c|c|c|c|c|}
\hline Name of plant \& parts & Ocimum sanctum & Cassia aurinculata & Datura metel & Carica papaya \\
\hline Kingdom & Plantae & Plantae & Plantae & Plantae \\
\hline Order & Lamiales & Fabales & Solanales & Brassicales \\
\hline Family & Lamiaceae & Fabaceae & Solanaceae & Caricaceae \\
\hline Genus & Ocimum & Senna & Datura & Carica \\
\hline Species & Sanctum & Auriculata & Metel & Papaya \\
\hline Other name & Tulsi & Ranvara & Datura & Papaya \\
\hline Plant parts used & Leaf & Leaf & Flower & Fruit \\
\hline
\end{tabular}

Table 2. Indication of colour change in silver nanoparticles solution

\begin{tabular}{|c|c|c|c|c|c|c|}
\hline S. No. & $\begin{array}{c}\text { Name of silver nanoparticle } \\
\text { synthesising solution }\end{array}$ & \multicolumn{2}{|c|}{ Colour Change } & $\begin{array}{c}\text { Colour } \\
\text { Intensity }\end{array}$ & Time & Result \\
\hline & Plant samples & Before & After & & & \\
\hline 1. & Datura metel & Yellowish & Dark brown & +++ & $1 \mathrm{hrs}$ & + \\
\hline 2. & Ocimum sanctum & Yellowish brown & Dark brown & +++ & $10 \mathrm{~min}$ & + \\
\hline 3. & Carica papaya & Watery & Dark brown & +++ & $5 \mathrm{hrs}$ & + \\
\hline 4 & Cassia aurinculata & Yellowish brown & Dark brown & +++ & $10 \mathrm{~min}$ & + \\
\hline
\end{tabular}

Result: - Positive $=+$, Negative $=-$, Colour intensity: - Light colour $=+$, Dark colour $=++$, Very dark colour $=$ $+++$

Table 3. Antimicrobial activity of silver nanoparticles

\begin{tabular}{|c|c|c|}
\hline Name of Plant & $\begin{array}{c}\text { Baterial activity } \\
(\mathbf{Z O I})\end{array}$ & $\begin{array}{c}\text { Antifungal activity } \\
(\mathbf{Z O I})\end{array}$ \\
\hline Ocimum sanctum & $7 \mathrm{~mm}$ & $5 \mathrm{~mm}$ \\
\hline Cassia auriculata & $10 \mathrm{~mm}$ & $5 \mathrm{~mm}$ \\
\hline Datura metel & $6 \mathrm{~mm}$ & --- \\
\hline Carica papaya & $5 \mathrm{~mm}$ & --- \\
\hline
\end{tabular}

